\title{
RIGHT ATRIAL MIGRATION OF NEPHROSTOMY CATHETER
}

\author{
ADERIVALDO C. DIAS-FILHO, GUILHERME A.V. COARACY, WALLACE BORGES
}

\author{
Urological Unit, Hospital de Base do Distrito Federal, Brasilia, Distrito Federal, Brazil
}

\begin{abstract}
Percutaneous tube nephrostomy (PTN) placement is associated with bleeding complications in a small proportion of cases. We study a case of inadvertent renal vein catheterization during PTN tube change with catheter right atrial migration treated by fluoroscopically monitored catheter removal.
\end{abstract}

Key words: nephrostomy, percutaneous; catheter; migration; right atrium

Int Braz J Urol. 2005; 31: 470-1

\section{CASE REPORT}

A 63-year-old female who previously underwent pelvic external beam radiotherapy for the treatment of uterine cervical carcinoma that was complicated by distal ureteral obstruction, underwent a CTguided left percutaneous tube nephrostomy (PTN) in August 2003. The catheter was being periodically changed over a guidewire. In March 2004, she came to the urology emergency room 3 days after losing the catheter, with urine dripping from the nephrostomy orifice. A 6F silicone catheter was negotiated with subsequent urine drainage. After 8 hours, this catheter was removed and a new nephrostomy was attempted over a $0.035 "$ angiographic guidewire inserted through the tract, without radiological monitoring. The tract was dilated under local anesthesia, a silicone 12F Foley catheter was placed there, and the balloon filled with $3 \mathrm{~mL}$ of diluted contrast.

After 1 hour, brisk bleeding was noted through the catheter, which eventually stopped due to tube obstruction from clotted blood. The patient felt dizziness, dyspnea and palpitations, but remained hemodynamically stable. A renal ultrasound did not show any perirenal fluid collection, but failed to locate the catheter. An abdominal CT displayed the catheter piercing the kidney's parenchyma, into the left renal vein and up the inferior vena cava (Figure-1). Chest radiography showed the Foley's balloon inflated on the topography of the right atrium (Figure-2). The balloon was deflated and brought about immediate resolution of her symptoms. A Doppler echocardiogram did not demonstrate atrial thrombi. With a cardiac surgery and anesthesiology team standing by, and with hemodynamic non-invasive monitoring, the catheter was pulled back under fluoroscopic visualization. After 5 days, a new CTguided left PTN was successfully placed under local anesthesia.

\section{COMMENTS}

Although hemorrhagic complications in PTN are not uncommon $(1,2)$, interventional treatment is not often necessary; renal artery angiography and embolization is required in $0.8 \%$ of the cases in a very large series (3). We were unable to find another report of inadvertent renal vein catheterization dur- 


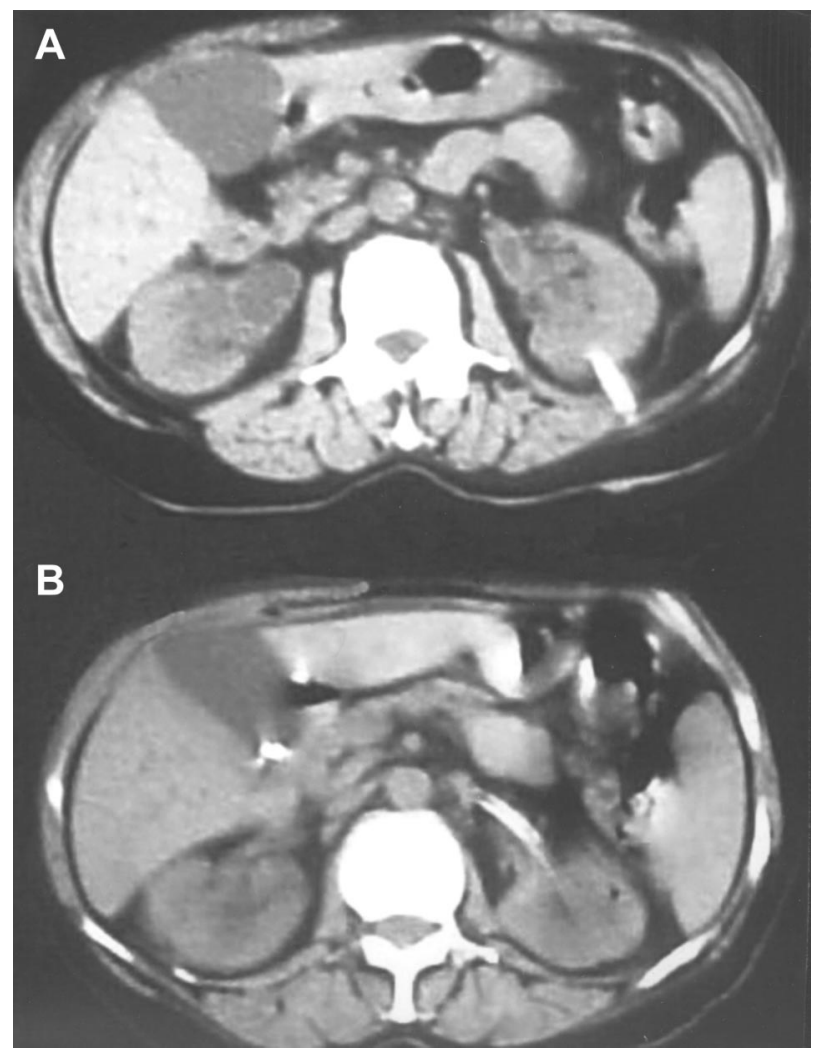

Figure 1 - A) Nephrostomy tube through renal parenchyma. B) Nephrostomy tube in left renal vein. A radiopaque gallbladder calculus can also be seen.

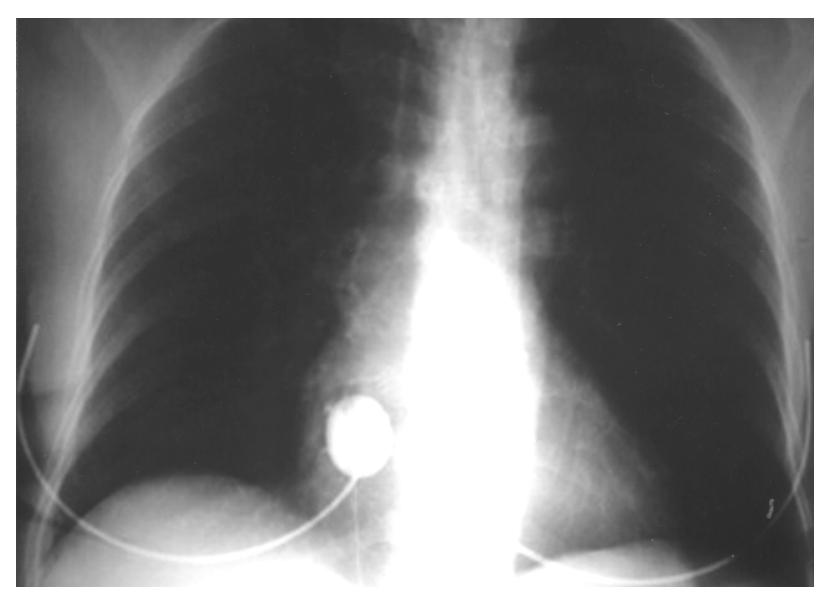

Figure 2 - Foley balloon in right atrium.

ing PTN. We suspect that the following chain of events took place: the guidewire perforated a major intrarenal tributary of the left renal vein, the dilation was performed through this injury and the catheter was placed inside the vessel, which simply followed the bloodstream to the right atrium. The patient's coagulation mechanisms were able not only to obstruct the catheter but also to avoid the formation of atrial thrombi and consequent pulmonary embolism.

The lesson learned from this case is that one should never manipulate nephrostomy tract without radiological orientation, even if urine is dripping from the skin orifice. The tract to the renal pelvis might be closed to instrumentation, and even the most delicate instrument is capable of injuring important structures, often with the direst consequences.

\section{REFERENCES}

1. McDougall EM, Liatsikos EM, Dinlenc CZ, Smith AD: Percutaneous Approaches to the Upper Urinary Tract. In: Campbell's Urology, 8th ed., Walsh PC et al. (eds.), Philadelphia, WB Saunders, 2002; pp. 3337-40.

2. Farrell TA, Hicks ME: A review of radiologically guided percutaneous nephrostomies in 303 patients. J Vasc Interv Radiol. 1997; 8: 769-74.

3. Kessaris DN, Bellman GC, Pardalidis NP, Smith AG: Management of hemorrhage after percutaneous renal surgery. J Urol. 1995; 153: 604-8.

Received: January 21, 2005

Accepted after revision: June 22, 2005

\section{Correspondence address:}

Dr. Aderivaldo C. Dias-Filho

Setor Medico Hospitalar Sul, Q 101, Bl A

Hospital de Base do Distrito Federal

Brasilia, DF, 70335-000, Brazil

E-mail: vadocabral@gmail.com 